\section{Observations of Water Trajectories in the Open Sea}

DIRECT observations of continuous movements of water masses in the open sea do not appear to have been carried out before. We have, for this purpose, for some years been using free drifting currentcrosses, followed by our research steamer the Skagerak. The crosses are made from two sheets of corrugated iron, intersecting at right angles, with the line of intersection vertical, and presenting an area to the current of approximately one square metre. They are suspended from a cylindrical buoy of small dimensions drifting at the surface with its axis vertical. The buoy carries a very light rod projecting upwards with a small electric lamp at the top, of the type used by drifters for their nets. By varying the length of the thin wire rope by which the cross is suspended from the buoy, one may study the water movements in different depths, since the small resistance due to the surface buoy does not affect the movements of the cross to any large extent, so long as the current below is not too weak relatively to the surface current. The positions of the buoy are observed at intervals of an hour or less by bringing up the ship as close to the drifting system as possible, without interfering with its movements. In daytime, with moderately strong currents, the movements of the buoy are followed from the ship at anchor by means of a Zeiss tele-meter. Such drifting systems have occasionally been followed right across the Skagerak from Skagen to the lighthouse Masseskär on the Swedish coast.

Last summer this method was found particularly useful for studies of the rotating currents discovered from the Skagerak in the central Baltic ${ }^{1}$. In order to determine the shifting positions of the drifting system as accurately as possible far from the shores (lat. $58^{\circ} 01^{\prime}$ N., long. $20^{\circ} 30^{\prime}$ W.), three large surface buoys carrying electric torches were anchored a few kilometres apart, by means of which the bearings of the ship following the drifting cross could be accurately found. With the cross at 10 metres below the surface the trajectories from thirty hours' observations were found to form two beautifully smooth loops, showing, beside the rotatory current, a general displacement towards the S.S.W. The rotating vector turned by a little more than $720^{\circ}$ in the same time. The period thus is about fourteen hours, in good agreement with previous observations on these 'inertia currents'. The details will be published in Svenska Hydrografisk-Biologiska Kommissionens skrifter.

Bornö Station.

Hans Pettersson.

BÖRJE KULLENBERG.

${ }^{1}$ NATERE, 131, 586, April 22, 1933.

\section{Ionospheric Investigations in Low Latitudes}

DURING the recent expedition of the "Consiglio Nazionale delle Ricerche" in Eritrea for studying cosmic rays, I made many observations by the echo method on the state of the ionosphere at Asmara (lat. $15^{\circ} 20^{\prime}$ N. ; long. $38^{\circ} 55^{\prime}$ E.), from September to November 1933. The most important results are as follows.

The limiting wave-length for the vertical reflection in region $F$ during the daylight hours reaches a minimum value between 26 and 28 metres towards six o'clock in the afternoon (local time) and not at noon as in the middle latitudes. In correspondence with this maximum of ionic density, waves between $140 \mathrm{~m}$. and the limiting wave are reflected at heights which differ by less than $5 \mathrm{~km}$.: this shows the formation of an extremely thin ionised layer.

The most interesting phenomenon that has been revealed from these observations is that, toward two o'clock in the morning, a very strong decrease of the limiting wave-length in region $F$ is frequently noted : it may pass from $60 \mathrm{~m}$. to $40 \mathrm{~m}$. (for the extraordinary ray) in an hour or two. Simultaneously, the virtual height of reflection decreases for all wave-lengths. After having shown this secondary nightly maximum, the ionic density decreases until about half an hour before sunrise, and then increases again during daylight. Another striking feature of the ionospheric conditions is the violent fading and complexity of echoes which accompany these nightly increases of ionic density. On many occasions I have observed the simultaneous rising of a particular type of atmospherics with continuous rustling.

Region $E$ presents a maximum of ionic density, which is always less than that of region $F$, and it is also sometimes subject to nightly increases of ionic density, chiefly in the early hours of night.

The observed phenomena, especially the nightly increases of ionic density in region $F$ and the occurrence of the daily maximum about six hours after the sun's radiation reaches its maximum, having regard to the geomagnetic latitude of Asmara $\left(11^{\circ} 30^{\prime}\right)$, cannot be explained as due to electrified corpuscles from the sun or other cosmic origin, which may be able to ionise the high atmosphere. At present, the only logical suggestion which can be formulated is C. T. R. Wilson's that the effects are due to the ionisation produced by the electric fields of thunderstorms, which undoubtedly reach very high values in tropical regions.

"A. Righi" Physical Institute, University of Bologna, Italy. 193.

${ }^{1}$ Proc. Phys. Soc., 37, 320: 1925. Proc. Roy. Soc., A, 141, 706;

\section{Vibrational Energy Levels of Hydrogen Cyanide}

THE infra-red spectrum of H.CN vapour has been examined with fairly high dispersion in the region near $2 \mu$. The following bands were observed:

\begin{tabular}{cll} 
Band & \multicolumn{1}{c}{$\begin{array}{c}\text { Position } \\
\nu_{2}+\nu_{3}\end{array}$} & $\begin{array}{c}\text { Character } \\
\text { (005.6 cm. }\end{array}$ \\
$\nu_{2}+2 \nu_{1}$ & $4993 \cdot 9$ & perpendicular \\
$\nu_{1}+\nu_{3}$ & $5405 \cdot 0$ & perpendicular \\
$2 \nu_{3}$ & $6523 \cdot 5$ & parallel \\
& & parallel
\end{tabular}

The band at 5405 is somewhat distorted, due to water vapour absorption in the same region, and its position is accurate only to within a few wave numbers. The discovery of the two perpendicular bands makes it possible to construct the complete vibrational energy level diagram of the normal molecule with a high degree of precision. In a report to appear in the near future the detailed analysis will be presented, and also the application of the results to the determination of the thermodynamic potentials of hydrogen cyanide.

A. ADEL.

E. F. BARKER.

University of Michigan,

Ann Arbor, U.S.A. 